\title{
Frequency and type of drug-related side effects necessitating treatment discontinuation in the Swiss Inflammatory Bowel Disease Cohort
}

\author{
Sébastien Godat ${ }^{\mathrm{a}}$, Nicolas Fournier ${ }^{\mathrm{d}}$, Ekaterina Safroneeva ${ }^{\mathrm{f}}$, Pascal Juillerat ${ }^{\mathrm{g}}$, Andreas Nydegger $^{\mathrm{b}}$, \\ Alex Straumann ${ }^{\mathrm{h}, \mathrm{i}}$, Stephan Vavricka, ${ }^{\mathrm{i}, \mathrm{j}}$, Luc Biedermann', Thomas Greuter', Montserrat Fragaa, \\ Karim Abdelrahman ${ }^{a}$, Dieter Hahnloser ${ }^{c}$, Bernhard Sauter ${ }^{k}$, Gerhard Rogler', Pierre Michetti, ${ }^{a, e}$ \\ and Alain M. Schoepfer ${ }^{\mathrm{a}}$; on behalf of the Swiss IBD Cohort Study Group
}

\begin{abstract}
Background and aim Systematic analyses of inflammatory bowel disease (IBD) drug-related side effects necessitating treatment cessation in large cohorts of patients with IBD are scarce. We aimed to assess the frequency and type of drug-related side effects requiring drug cessation in patients included in the Swiss IBD Cohort.

Patients and methods A retrospective review was performed of data from the Swiss IBD Cohort physician questionnaires documenting a treatment cessation for the following drug categories: aminosalicylates, topical and systemic steroids, thiopurines, methotrexate, tumor necrosis factor-antagonists, and calcineurin inhibitors (tacrolimus, cyclosporine).

Results A total of 3192 patients were analyzed, of whom 1792 (56.1\%) had Crohn's disease, 1322 (41.4\%) had ulcerative colitis, and $78(2.5 \%)$ had IBD unclassified. Of 3138 patients treated with IBD drugs, $2129(67.8 \%)$ presented with one or several drug-related side effects necessitating drug cessation. We found a significant positive correlation between the number of concomitantly administered IBD drugs and the occurrence of side effects requiring drug cessation $(P<0.001)$. Logistic regression modeling identified Crohn's disease diagnosis [odds ratio $(\mathrm{OR})=1.361, P=0.017$ ], presence of extraintestinal manifestations ( $\mathrm{OR}=2.262, P<0.001)$, IBD-related surgery $(\mathrm{OR}=1.419, P=0.006)$, and the increasing number of concomitantly used IBD drugs [OR $=2.007(P<0.001)$ for two concomitantly used IBD drugs; $\mathrm{OR}=3.225(P<0.001)$ for at least three concomitantly used IBD drugs] to be associated significantly with the occurrence of IBD drug-related adverse events that necessitated treatment cessation.

Conclusion Physicians should keep in mind that the number of concomitantly administered IBD drugs is the main risk factor for drug-related adverse events necessitating treatment cessation. Eur J Gastroenterol Hepatol 00:000-000

Copyright () 2018 Wolters Kluwer Health, Inc. All rights reserved.
\end{abstract}

\section{Introduction}

Crohn's disease (CD) and ulcerative colitis (UC) represent the two main types of inflammatory bowel disease (IBD) $[1,2]$. There is increasing evidence that IBD results from an

European Journal of Gastroenterology \& Hepatology 2018, 00:000-000

Keywords: drug-related side effect, inflammatory bowel disease therapy, inflammatory bowel disease

${ }^{a}$ Division of Gastroenterology and Hepatology, ${ }^{b}$ Division of Pediatric Gastroenterology and Nutrition, "Division of Visceral Surgery, Lausanne University Hospital, University of Lausanne, dinstitute of Social and Preventive Medicine (IUMSP), Lausanne University Hospital, ${ }^{e} \mathrm{Crohn}$ and Colitis Center, Clinique La Source, Lausanne, "Institute of Social and Preventive Medicine, University of Bern, gDivision of Gastroenterology and Hepatology, University Hospital Bern, Bern, nSwiss EoE Center, Pediatrician Römerhof, Olten, 'Division of Gastroenterology and Hepatology, University Hospital Zurich, 'Division of Gastroenterology and Hepatology, Triemli Hospital and kGastroCenter Hirslanden Zurich, Zurich, Switzerland

Correspondence to Alain M. Schoepfer, MD, Division of Gastroenterology and Hepatology, Lausanne University Hospital, University of Lausanne, Rue du Bugnon 44, 1011 Lausanne, Switzerland

Tel: +41 21314 2394; fax: +4121314 4718; e-mail: alain.schoepfer@chuv.ch Received 9 July 2017 Accepted 4 October 2017

Supplemental Digital Content is available for this article. Direct URL citations appear in the printed text and are provided in the HTML and PDF versions of this article on the journal's website, www.eurojgh.com. inappropriate inflammatory response to intestinal microbes in a genetically susceptible host $[1,2]$. The majority of IBD patients will suffer from a chronic disease course with the development of tissue damage related to the long-standing inflammatory activity [3]. As such, the vast majority of IBD patients will need long-term anti-inflammatory treatments, not only for short-term symptom control but also to reduce the risk of subsequent bowel damage [4,5].

Inevitably, IBD drugs may also be associated with drugrelated side effects [6]. Examples include dermatological complications such as the development of a paradoxical psoriasiform skin reaction under tumor necrosis factor (TNF)-antagonist therapy or an increased risk of nonmelanomatous skin cancer under thiopurines [7]. The frequency and type of side effects of drugs used for IBD treatment are typically reported in the medical literature on the basis of the use of single drugs [8]. However, in daily practice, IBD drugs are frequently combined. Examples include the use of combined therapy with azathioprine and infliximab that has been associated with better clinical and endoscopic remission rates in $\mathrm{CD}$ patients naive to treatment when combined with the single use of either infliximab and azathioprine and the combined use of these substances in $\mathrm{CD}$ patients to reduce the risk for anti-TNF-antagonist antibody formation $[9,10]$. 
However, the multiplicity of treatments may increase the likelihood of development of side effects. For instance, although monotherapy with adalimumab was not associated with an increase in malignancies, combination therapy with azathioprine clearly was [11].

Given the fact that there is a paucity of cohort studies providing a global view of the type and frequency of drugrelated adverse events, we initiated this investigation to address the following questions: first, what is the frequency and type of adverse events related to single drug treatments in IBD patients? Second, what is the frequency of adverse events related to the use of multiple (at least two) drug treatments in IBD patients? Third, do particular risk factors besides the use of the drug itself exist that can be linked to the occurrence of drug-related side effects?

\section{Patients and methods}

\section{Patients}

The Swiss Inflammatory Bowel Disease Cohort (SIBDC) has been including IBD patients from all regions of Switzerland since 2006. The SIBDC is supported by the Swiss National Science Foundation and is approved by local ethics committees [12]. For inclusion, patients have to be at least 18 years old and need to provide written informed consent. In addition, a permanent residence status in Switzerland and/or Swiss health insurance coverage is mandatory. Patients can be included in the cohort if a diagnosis of CD, UC, or IBD unclassified has been established at least 4 months before inclusion, or if they had at least one episode of symptom recurrence [12]. Patients are prospectively included if the diagnosis of IBD has been established in 2006 or later; a retrospective inclusion of patients diagnosed with IBD in 2005 and earlier is also possible. At the time of inclusion, patients undergo a thorough clinical and laboratory assessment. Clinical, socioeconomic, and psychosocial data are collected. The treating physicians complete physician-reported outcomes, whereas the patients complete patient-reported outcomes such as questionnaires on quality of life. Disease location is recorded according to the Montréal classification [13]. After enrollment, patients and physicians complete a yearly follow-up questionnaire. Patients included in this study were recruited in the following settings of care: $61 \%$ in university hospitals, $13 \%$ in large nonuniversity hospitals, $6 \%$ in regional hospitals, and $20 \%$ in private practices.

\section{Methods}

The collected data were entered into a Microsoft Access database (Access 2000; Microsoft Switzerland Ltd Liab. Co., Wallisellen, Switzerland) at the datacenter of the SIBDC, which is located at the Institute of Social and Preventive Medicine, University of Lausanne. For the purpose of this manuscript, the analysis was based on the validated data obtained from IBD patients enrolled into the SIBDC between May 2006 and April 2016 (10 years period). Data were extracted from physician questionnaires that record on-treatment adverse events that required drug cessation during the entire disease history. The following drug categories were analyzed: aminosalicylates [5-aminosalicylic acid (5-ASA)], steroids [topical (budesonide capsules or enema) and systemic steroids were analyzed separately], thiopurines, methotrexate, TNF-antagonists, and calcineurin inhibitors (tacrolimus, cyclosporine). The follow-up questionnaires of the cohort do not assess the time interval (months) at which the particular drug was administered, and they also did not capture any follow-up information after a particular adverse event had developed that led to drug cessation.

\section{Statistical analysis}

Data were retrieved from the database of the SIBDC at the Institute of Social and Preventive Medicine of University of Lausanne. All statistical analyses were carried out by the cohort statistician (N.F.) using the statistical package program Stata (version 12.1; StataCorp., College Station, Texas, USA). Quantitative data distribution was analyzed using normal-QQ-plots. Results of quantitative data are presented either as median plus interquartile ranges (for data with a non-Gaussian distribution) or as mean $\pm S D$ and range (for normally distributed data). Categorical data were summarized as the percentage of the group total. For quantitative data, differences in distribution between two groups were evaluated using either the Wilcoxon-Mann-Whitney rank test (for data with a nonGaussian distribution) or the Student $t$-test (for normally distributed data). For categorical outcomes, differences in the observed frequencies between groups were compared using the $\chi^{2}$-test or the exact Fisher's test for groups with a small number of observations $(n<20)$. A Bonferroni adjustment was used throughout in case of multiple testing. A $P$-value of less than 0.05 was considered statistically significant. Stepwise multiple logistic regression modeling was performed to evaluate the association between potential risk factors and the appearance of drug-related adverse events leading to drug cessation. The variables tested as potential risk factors were sex, age at the time of IBD diagnosis, disease duration, IBD family history, presence of extraintestinal manifestations (EIM), smoking status, BMI, IBD-related surgery, and the number of concomitantly used IBD drugs. In a first step, the potential risk factors were each tested separately. In a second step, all risk factors with a $P$-value less than 0.2 were entered together into the multivariate logistic regression model.

\section{Results}

\section{Baseline characteristics}

A total of 3192 patients were included, of whom 1792 $(56.1 \%)$ had CD, $1322(41.4 \%)$ had UC, and $78(2.5 \%)$ had IBD unclassified. Of 3138 patients treated with IBD drugs, $2129(67.8 \%)$ presented with one or several drug-related side effects that required drug cessation (Table 1). Disease duration of IBD patients with and without treatment adverse events was similar (median 12 years for both groups, $P=0.675$ ). The age at enrollment into the SIBDC was again similar between the groups with and without therapy adverse events that necessitated a drug cessation. No relevant differences were noted with respect to disease location for CD and UC between the groups with and without treatment adverse events. It is noteworthy that IBD patients who experienced drug-related side effects underwent combined treatments with two and more IBD drugs significantly more frequently compared with IBD patients without drug-related side effects $(P<0.001)$. 
Table 1. Clinical characteristics of patients

\begin{tabular}{|c|c|c|c|c|}
\hline & $\begin{array}{l}\text { Patients with } \\
\text { adverse drug } \\
\text { event }\end{array}$ & $\begin{array}{l}\text { Patients } \\
\text { without } \\
\text { adverse drug } \\
\text { event }\end{array}$ & $\begin{array}{c}\text { Patients } \\
\text { never treated } \\
\text { with any IBD } \\
\text { drugs }\end{array}$ & $P$-value ${ }^{a}$ \\
\hline $\begin{array}{l}\text { Total number of all IBD } \\
\text { patients }\end{array}$ & $2129(66.7)$ & 1009 (31.6) & $54(1.7)$ & - \\
\hline Sex & & & - & $<0.001$ \\
\hline Male & 1127 (52.9) & $456(45.2)$ & & \\
\hline Female & $1002(47.1)$ & $553(54.8)$ & & \\
\hline Diagnosis & & & - & $<0.001$ \\
\hline$C D$ & $1140(53.6)$ & $633(62.7)$ & & \\
\hline UC & $936(44.0)$ & $355(35.2)$ & & \\
\hline IBDU & $53(2.5)$ & $21(2.1)$ & & \\
\hline $\begin{array}{l}\text { Age at diagnosis } \\
\text { (years) }\end{array}$ & & & - & 0.382 \\
\hline Median & 25 & 28 & & \\
\hline IQR & $21-37$ & $20-39$ & & \\
\hline Range & $1-83$ & $5-80$ & & \\
\hline $\begin{array}{l}\text { Age at enrollment } \\
\text { (years) }\end{array}$ & & & - & 0.195 \\
\hline Median & 40 & 39 & & \\
\hline IQR & $29-52$ & $29-51$ & & \\
\hline Range & $18-88$ & $18-82$ & & \\
\hline $\begin{array}{l}\text { Age at latest follow- } \\
\text { up (years) }\end{array}$ & & & - & 0.656 \\
\hline Median & 45 & 43 & & \\
\hline IQR & $33-57$ & $33-56$ & & \\
\hline Range & $18-93$ & $18-86$ & & \\
\hline $\begin{array}{l}\text { Disease duration } \\
\text { (years) }\end{array}$ & & & - & 0.675 \\
\hline Median & 12 & 12 & & \\
\hline IQR & $6-20$ & $7-19$ & & \\
\hline Range & $0-59$ & $0-57$ & & \\
\hline $\begin{array}{l}\text { Smoking status at } \\
\text { diagnosis }\end{array}$ & & & - & 0.013 \\
\hline Nonsmoker & $1320(62.0)$ & 579 (57.4) & & \\
\hline Smoker & 718 (33.7) & $394(39.1)$ & & \\
\hline Unknown & $91(4.3)$ & $36(3.5)$ & & \\
\hline $\begin{array}{l}\text { Number of IBD } \\
\text { treatments }\end{array}$ & & & - & $<0.001$ \\
\hline 1 & $326(15.3)$ & $12(1.2)$ & & \\
\hline 2 & $585(27.5)$ & $62(6.1)$ & & \\
\hline 3 or more & $1218(57.2)$ & 935 (92.7) & & \\
\hline CD patients & $1140(63.6)$ & 633 (35.3) & $19(1.1)$ & \\
\hline Sex & & & - & $<0.001$ \\
\hline Male & $584(51.2)$ & $261(41.2)$ & & \\
\hline Female & $556(48.8)$ & 372 (58.8) & & \\
\hline $\begin{array}{l}\text { Age at diagnosis } \\
\text { (years) }\end{array}$ & & & - & 0.738 \\
\hline Median & 26 & 25 & & \\
\hline IQR & $20-36$ & $20-37$ & & \\
\hline Range & $1-81$ & $5-80$ & & \\
\hline $\begin{array}{l}\text { Age at enrollment } \\
\text { (years) }\end{array}$ & & & - & 0.175 \\
\hline Median & 39 & 38 & & \\
\hline IQR & $28-51$ & $27-50$ & & \\
\hline Range & $18-88$ & $18-81$ & & \\
\hline $\begin{array}{l}\text { Age at latest follow- } \\
\text { up (years) }\end{array}$ & & & - & 0.426 \\
\hline Median & 44 & 42 & & \\
\hline IQR & $32-57$ & $32-55$ & & \\
\hline Range & $18-93$ & $18-86$ & & \\
\hline $\begin{array}{l}\text { Disease duration } \\
\text { (years) }\end{array}$ & & & - & 0.741 \\
\hline Median & 13 & 12 & & \\
\hline IQR & $7-22$ & $7-20$ & & \\
\hline Range & $0-59$ & $0-57$ & & \\
\hline $\begin{array}{l}\text { Smoking status at } \\
\text { diagnosis }\end{array}$ & & & - & 0.026 \\
\hline Nonsmoker & $577(50.6)$ & $292(46.1)$ & & \\
\hline Smoker & $507(44.5)$ & $320(50.6)$ & & \\
\hline Unknown & $56(4.9)$ & 21 (3.3) & & \\
\hline $\begin{array}{l}\text { Number of IBD } \\
\text { treatments }\end{array}$ & & & - & $<0.001$ \\
\hline 1 & $138(12.1)$ & $2(0.3)$ & & \\
\hline 2 & $294(25.8)$ & $38(6.0)$ & & \\
\hline 3 or more & $708(62.1)$ & 593 (93.7) & & \\
\hline
\end{tabular}

Table 1. (Continued)

\begin{tabular}{|c|c|c|c|c|}
\hline & $\begin{array}{l}\text { Patients with } \\
\text { adverse drug } \\
\text { event }\end{array}$ & $\begin{array}{l}\text { Patients } \\
\text { without } \\
\text { adverse drug } \\
\text { event }\end{array}$ & $\begin{array}{c}\text { Patients } \\
\text { never treated } \\
\text { with any IBD } \\
\text { drugs }\end{array}$ & $P$-value ${ }^{\text {a }}$ \\
\hline $\begin{array}{l}\text { Disease location at } \\
\text { diagnosis }\end{array}$ & & & - & 0.445 \\
\hline L1 (ileal) & $261(22.9)$ & $157(24.8)$ & & \\
\hline L2 (colonic) & $251(22.0)$ & $116(18.3)$ & & \\
\hline L3 (ileocolonic) & $502(44.0)$ & $291(46.0)$ & & \\
\hline L4 only (upper GI) & $9(0.8)$ & $5(0.8)$ & & \\
\hline Unknown/unclear & $117(10.3)$ & $64(10.1)$ & & \\
\hline $\begin{array}{l}\text { Disease location at } \\
\text { the latest follow-up }\end{array}$ & & & - & 0.837 \\
\hline L1 (ileal) & $339(29.7)$ & $194(30.7)$ & & \\
\hline L2 (colonic) & $0.391(34.3)$ & $206(32.5)$ & & \\
\hline L3 (ileocolonic) & $365(32.0)$ & $202(31.9)$ & & \\
\hline L4 only (upper GI) & $24(2.1)$ & $17(2.7)$ & & \\
\hline Unknown/unclear & $21(1.8)$ & $14(2.2)$ & & \\
\hline UC/IBDU patients [n (\%)] & $989(70.6)$ & $376(26.9)$ & $35(2.5)$ & \\
\hline Sex & & & - & 0.314 \\
\hline Male & $543(54.9)$ & $195(51.9)$ & & \\
\hline Female & $446(45.1)$ & $181(48.1)$ & & \\
\hline $\begin{array}{l}\text { Age at diagnosis } \\
\text { (years) }\end{array}$ & & & - & 0.857 \\
\hline Median & 31 & 31 & & \\
\hline IOR & $23-40$ & $23-42$ & & \\
\hline Range & $3-83$ & $10-78$ & & \\
\hline $\begin{array}{l}\text { Age at enrollment } \\
\text { (years) }\end{array}$ & & & - & 0.773 \\
\hline Median & 41 & 42 & & \\
\hline IQR & $31-52$ & $31-53$ & & \\
\hline Range & $18-85$ & $18-82$ & & \\
\hline $\begin{array}{l}\text { Age at latest follow- } \\
\text { up (years) }\end{array}$ & & & - & 0.352 \\
\hline Median & 45 & 46 & & \\
\hline IQR & $35-56$ & $36-58$ & & \\
\hline Range & $18-89$ & $18-85$ & & \\
\hline $\begin{array}{l}\text { Disease duration } \\
\text { (years) }\end{array}$ & & & - & 0.657 \\
\hline Median & 11 & 11 & & \\
\hline IQR & $6-18$ & $7-17$ & & \\
\hline Range & $0-50$ & $0-52$ & & \\
\hline $\begin{array}{l}\text { Smoking status at } \\
\text { diagnosis }\end{array}$ & & & - & 0.756 \\
\hline Nonsmoker & $743(75.1)$ & $287(76.3)$ & & \\
\hline Smoker & $211(21.3)$ & $74(19.7)$ & & \\
\hline Unknown & $35(3.5)$ & $15(4.0)$ & & \\
\hline $\begin{array}{l}\text { Number of IBD } \\
\text { treatments }\end{array}$ & & & - & $<0.001$ \\
\hline 1 & $188(19.0)$ & $10(2.7)$ & & \\
\hline 2 & $291(29.4)$ & $24(6.4)$ & & \\
\hline$\geq 3$ & $510(51.6)$ & $342(91.0)$ & & \\
\hline $\begin{array}{l}\text { Disease location at } \\
\text { diagnosis }\end{array}$ & & & - & 0.002 \\
\hline Pancolitis & $366(37.0)$ & $155(41.2)$ & & \\
\hline Left-sided colitis & 315 (31.9) & $121(32.2)$ & & \\
\hline Proctitis & $219(22.1)$ & $52(13.8)$ & & \\
\hline Unknown/unclear & $89(9.0)$ & $48(12.8)$ & & \\
\hline $\begin{array}{l}\text { Disease location at } \\
\text { enrollment }\end{array}$ & & & - & 0.033 \\
\hline Pancolitis & $373(37.7)$ & $156(41.5)$ & & \\
\hline Left-sided colitis & $368(37.2)$ & $154(41.0)$ & & \\
\hline Proctitis & $228(23.1)$ & $60(16.0)$ & & \\
\hline Unknown/unclear & $20(2.0)$ & $6(1.6)$ & & \\
\hline
\end{tabular}

Data are presented as $n(\%)$.

Disease location is indicated according to the Montreal classification [13].

$\mathrm{CD}$, Crohn's disease; IBD, inflammatory bowel disease; IBDU, inflammatory bowel disease of undetermined origin; IOR, interquartile range; UC, ulcerative colitis.

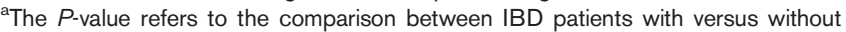
adverse drug event.

\section{Frequencies and types of inflammatory bowel disease drug-related adverse events}

In Table 2, we present the IBD drug-related adverse events during the entire disease course stratified according to IBD 
Table 2. Frequency of adverse drug events necessitating drug discontinuation in inflammatory bowel disease patients

\begin{tabular}{|c|c|c|c|c|}
\hline Drug category & $\mathrm{CD}[n(\%)]$ & UC $[n(\%)]$ & IBDU [n (\%)] & Total $[n(\%)]$ \\
\hline Aminosalicylates & 70/1033 (6.8) & $108 / 1243(8.7)$ & $6 / 67(9.0)$ & $184 / 2343(7.9)$ \\
\hline Budesonide & $47 / 847(5.6)$ & $26 / 532(4.9)$ & $2 / 30(6.7)$ & $75 / 1409$ (5.3) \\
\hline Prednisone & $63 / 1292(4.9)$ & $42 / 941(4.5)$ & $2 / 54$ (3.7) & $107 / 2287(4.7)$ \\
\hline Azathioprine & $339 / 1337$ (25.4) & 179/733 (24.4) & $13 / 48(27.1)$ & $531 / 2118(25.1)$ \\
\hline 6-Mercaptopurine & $79 / 253$ (31.2) & $44 / 154(28.6)$ & $2 / 8(25.0)$ & $125 / 415(30.1)$ \\
\hline Methotrexate & 74/379 (19.5) & $24 / 112(21.4)$ & $2 / 14(14.3)$ & $100 / 505$ (19.8) \\
\hline Cyclosporine & $3 / 27(11.1)$ & $14 / 95(14.7)$ & $0 / 4(0.0)$ & $17 / 126(13.5)$ \\
\hline Infliximab & $201 / 938$ (21.4) & $71 / 401(17.7)$ & 10/33 (30.3) & $282 / 1372(20.6)$ \\
\hline Adalimumab & $74 / 481(15.4)$ & $11 / 109(10.1)$ & 2/15 (13.3) & $87 / 605(14.4)$ \\
\hline Certolizumab & $37 / 231(16.0)$ & $0 / 11(0.0)$ & $0 / 4(0.0)$ & $37 / 246(15.0)$ \\
\hline
\end{tabular}

$\mathrm{CD}$, Crohn's disease; IBDU, inflammatory bowel disease of undetermined origin; UC, ulcerative colitis.

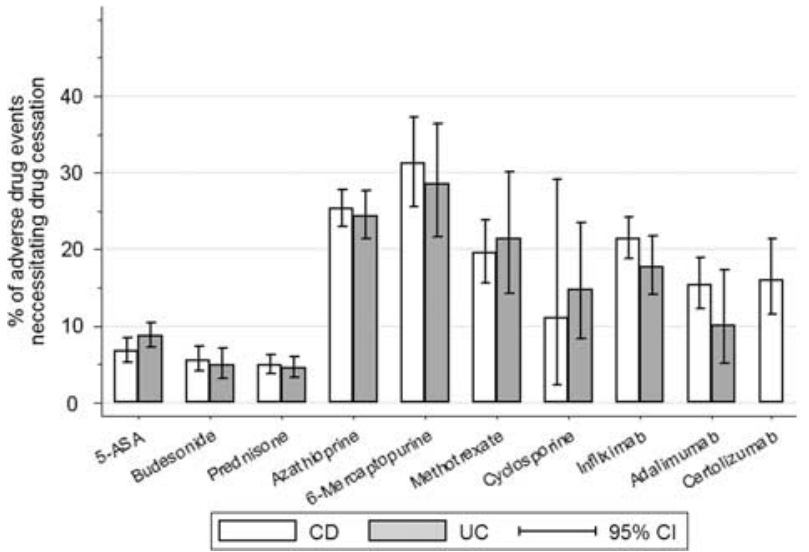

Fig. 1. Frequency of drug adverse events necessitating drug cessation in inflammatory bowel disease patients during their entire disease history stratified according to inflammatory bowel disease diagnosis. 5-ASA, 5-aminosalicylic acid; CD, Crohn's disease; CI, confidence interval; UC, ulcerative colitis.

type. The lowest frequency of IBD drug adverse events necessitating drug cessation was observed for topical and systemic steroids (5.3 and $4.7 \%$ ), followed by aminosalicylates $(7.9 \%)$. The frequency of drug-related side effects necessitating treatment discontinuation for azathioprine, mercaptopurine, and methotrexate was 25.1, 30.1, and $19.8 \%$, respectively. Figure 1 shows the frequency of drugrelated side effects necessitating drug cessation in IBD patients during their entire disease history, stratified according to IBD diagnosis.

A detailed overview of the distinct types of IBD drugrelated adverse events, stratified according to distinct drug classes and IBD diagnosis, is available in Supplementary Table 1 (Supplemental digital content 1, http://links.lww.com/ EJGH/A258). Use of 5-ASA was generally associated with a low prevalence of adverse drug reactions that necessitated drug cessation. Nephritis requiring 5-ASA cessation was observed in $0.3 \%$ of patients. Steroids had to be stopped in $0.2 \%$ of treated patients because of osteopenia/osteoporosis, in $0.2 \%$ of treated patients because of psychological intolerance, and in $0.1 \%$ of steroid-treated patients because of diabetes. Mercaptopurine had to be discontinued because of leukopenia, hepatotoxicity, and pancreatitis in $2.7,2.3$, and $1.1 \%$ of treated patients, respectively. Azathioprine had to be stopped because of leukopenia, hepatotoxicity, and pancreatitis in $1.2,0.8$, and $1.2 \%$, respectively. No lymphoma was reported in patients being treated with thiopurines. In $0.3 \%$ of patients treated with methotrexate, a discontinuation of therapy because of liver fibrosis/cirrhosis was reported. Gastrointestinal intolerance necessitated methotrexate cessation in $4.8 \%$ of treated patients.
Cyclosporine had to be stopped in $3.8 \%$ of treated patients because of renal hypertension. Hypersensitivity reactions necessitating drug cessation were documented in $2.5 \%$ of patients under infliximab compared with $1.0 \%$ of patients under adalimumab and $1.8 \%$ of patients under certolizumab. We identified one patient with pulmonary tuberculosis who required infliximab cessation. There was no tuberculosis case requiring cessation of treatment with adalimumab and certolizumab, respectively. The overall rate of infections necessitating the cessation of TNF-antagonists was very low $[0 \%, 95 \%$ confidence interval (CI): $0-1.7 \%]$. Injection-site reactions required adalimumab discontinuation in $0.2 \%$ of treated patients. The three different TNF-antagonists had a similar distribution in the frequency of other adverse events such as asthenia, fever, headache, arthralgia, nausea, or abdominal pain requiring drug cessation.

\section{Frequency and type of inflammatory bowel disease drug- related adverse events in patients under combined regimens}

We analyzed the prevalence of drug-related side effects necessitating drug discontinuation in relation to the number of IBD drugs used. The majority of drug-related side effects that required drug cessation developed in IBD patients under monotherapy with an IBD drug (Table 3).

The number of concomitantly used IBD drugs increased the risk for the development of IBD drug-related adverse events that required IBD drug cessation (Table 4). When looking at all IBD patients together, patients under IBD drug monotherapy had a cumulative frequency of $10.3 \%$ of drug-related side effects that necessitated drug cessation. This risk increased to $19.0 \%$ in IBD patients being treated with two IBD drugs and $26.0 \%$ in IBD patients being treated with at least three IBD drugs (Table 4). CD patients more frequently developed IBD drug-related side effects that necessitated drug cessation compared with UC patients $(12.5$ vs. $6.8 \%$ for patients under monotherapy, $P=0.001 ; 21.3$ vs. $15.2 \%$ for patients under combined therapy with two drugs, $P=0.010$; and 33.3 vs. $21.1 \%$ for patient treated with at least three IBD drugs, $P=0.002$ ). Figure 2 shows the frequency of drug-related adverse events requiring IBD drug cessation in relation to the number of concomitantly used IBD drugs.

\section{Systematic analysis of risk factors for inflammatory bowel disease drug-related adverse events necessitating treatment discontinuation}

We systematically analyzed the risk for the occurrence of IBD drug-related side effects necessitating cessation of 
treatment by the means of logistic regression modeling. We first analyzed the risk factors for IBD drug-related side effects in the entire IBD population (Table 5). In the univariate logistic regression model, we found that female sex, $\mathrm{CD}$ diagnosis, the presence of EIM, IBD-related surgery, and the number of concomitantly used IBD drugs were

Table 3. Frequency of adverse events depending on the type of drug and the number of concomitant treatments used

\begin{tabular}{|c|c|c|c|}
\hline & $\begin{array}{l}\text { CD patients } \\
{[n(\%)]}\end{array}$ & $\begin{array}{l}\text { UC patients } \\
{[n(\%)]}\end{array}$ & $\begin{array}{l}\text { All patients } \\
{[n(\%)]}\end{array}$ \\
\hline \multicolumn{4}{|l|}{ 5-ASA side effect } \\
\hline Under monotherapy & $15(93.8)$ & $21(60.0)$ & $36(70.6)$ \\
\hline Under therapy with two drugs & $1(6.2)$ & $12(34.3)$ & $13(25.5)$ \\
\hline $\begin{array}{l}\text { Under therapy with at least three } \\
\text { drugs }\end{array}$ & $0(0.0)$ & $2(5.7)$ & $2(3.9)$ \\
\hline \multicolumn{4}{|l|}{ Cyclosporine side effect } \\
\hline Under monotherapy & $0(0.0)$ & $2(25.0)$ & $2(20.0)$ \\
\hline Under therapy with two drugs & $1(50.0)$ & $4(50.0)$ & $5(50.0)$ \\
\hline $\begin{array}{l}\text { Under therapy with at least three } \\
\text { drugs }\end{array}$ & $1(50.0)$ & $2(25.0)$ & $3(30.0)$ \\
\hline \multicolumn{4}{|l|}{ Azathioprine side effect } \\
\hline Under monotherapy & $70(89.6)$ & $35(55.6)$ & $105(69.5)$ \\
\hline Under therapy with two drugs & $17(19.3)$ & 21 (33.3) & $38(25.2)$ \\
\hline $\begin{array}{l}\text { Under therapy with at least three } \\
\text { drugs }\end{array}$ & $1(1.1)$ & $7(11.1)$ & $8(5.3)$ \\
\hline \multicolumn{4}{|l|}{ 6-Mercaptopurine side effect } \\
\hline Under monotherapy & $24(77.4)$ & $14(63.6)$ & $38(71.7)$ \\
\hline Under therapy with two drugs & $6(19.4)$ & $6(27.3)$ & $12(22.6)$ \\
\hline $\begin{array}{l}\text { Under therapy with at least three } \\
\text { drugs }\end{array}$ & $1(3.2)$ & $2(9.1)$ & $3(5.7)$ \\
\hline \multicolumn{4}{|l|}{ Methotrexate side effect } \\
\hline Under monotherapy & $24(66.7)$ & $6(50.0)$ & $30(62.5)$ \\
\hline Under therapy with two drugs & $9(25.0)$ & $2(16.7)$ & $11(22.9)$ \\
\hline $\begin{array}{l}\text { Under therapy with at least three } \\
\text { drugs }\end{array}$ & $3(8.3)$ & $4(33.3)$ & $7(14.6)$ \\
\hline \multicolumn{4}{|l|}{ Infliximab side effect } \\
\hline Under monotherapy & $96(76.2)$ & $27(56.3)$ & $123(70.7)$ \\
\hline Under therapy with two drugs & 27 (21.4) & 15 (31.3) & $42(24.1)$ \\
\hline $\begin{array}{l}\text { Under therapy with at least three } \\
\text { drugs }\end{array}$ & $2(2.4)$ & $6(12.5)$ & $9(5.2)$ \\
\hline \multicolumn{4}{|l|}{ Adalimumab side effect } \\
\hline Under monotherapy & $37(72.6)$ & $5(55.6)$ & $42(70.0)$ \\
\hline Under therapy with two drugs & $12(23.5)$ & $3(33.3)$ & $15(25.0)$ \\
\hline $\begin{array}{l}\text { Under therapy with at least three } \\
\text { drugs }\end{array}$ & $2(3.9)$ & $1(11.1)$ & $3(5.0)$ \\
\hline \multicolumn{4}{|l|}{ Certolizumab side effect } \\
\hline Under monotherapy & $16(51.6)$ & $0(0.0)$ & $16(51.6)$ \\
\hline Under therapy with two drugs & $14(45.2)$ & $0(0.0)$ & $14(45.2)$ \\
\hline $\begin{array}{l}\text { Under therapy with at least three } \\
\text { drugs }\end{array}$ & $1(3.2)$ & $0(0.0)$ & $1(3.2)$ \\
\hline \multicolumn{4}{|l|}{ Budesonide side effect } \\
\hline Under monotherapy & $5(50.0)$ & $1(20.0)$ & $6(40.0)$ \\
\hline Under therapy with two drugs & $4(40.0)$ & $2(40.0)$ & $6(40.0)$ \\
\hline $\begin{array}{l}\text { Under therapy with at least three } \\
\text { drugs }\end{array}$ & $1(10.0)$ & $2(40.0)$ & $3(20.0)$ \\
\hline \multicolumn{4}{|l|}{ Prednisone side effect } \\
\hline Under monotherapy & $9(60.0)$ & $5(62.5)$ & $14(60.9)$ \\
\hline Under therapy with two drugs & 5 (33.3) & $2(25.0)$ & $7(30.4)$ \\
\hline $\begin{array}{l}\text { Under therapy with at least three } \\
\text { drugs }\end{array}$ & $1(6.7)$ & $1(12.5)$ & $2(8.7)$ \\
\hline
\end{tabular}

5-ASA, 5-aminosalicylic acid; CD, Crohn's disease; UC, ulcerative colitis. associated significantly with an increased risk for the occurrence of IBD drug-related side effects necessitating discontinuation of drug. There was also a trend for disease duration more than 10 years to be associated with the risk of drug-related adverse events requiring discontinuation of drug. All factors from the univariate analysis with a $P$-value less than 0.2 were entered into the multivariate model. In the multivariate model, we identified CD diagnosis [odds ratio $(\mathrm{OR})=1.361$ ], presence of EIM $(\mathrm{OR}=2.262)$, IBD-related surgery $(\mathrm{OR}=1.419)$, and the increasing number of concomitantly used IBD drugs $(\mathrm{OR}=2.007$ for two concomitantly used IBD drugs; $\mathrm{OR}=3.225$ for at least three concomitantly used IBD drugs) to be associated significantly with the occurrence of IBD drug-related adverse events that necessitated drug cessation. The use of at least three concomitantly used IBD drugs showed the strongest association with IBD drugrelated adverse events necessitating drug cessation among all the analyzed risk factors.

The analyses for CD and UC patients are shown in Supplementary Tables 2 and 3 (Supplemental digital content 1, http://links.lww.com/EJGH/A258). In CD patients, the multivariate model identified the presence of EIM $(\mathrm{OR}=2.556)$, IBD-related surgery $(\mathrm{OR}=1.367)$, and the number of concomitantly used IBD drugs $(\mathrm{OR}=1.906$ for two concomitantly used IBD drugs; $\mathrm{OR}=3.589$ for at least three concomitantly used IBD drugs) to be associated significantly with IBD drug-related side effects requiring drug cessation. Again, the use of at least three concomitantly used IBD drugs showed the strongest association with IBD drug-related adverse events necessitating drug cessation among all the analyzed risk factors (Supplementary

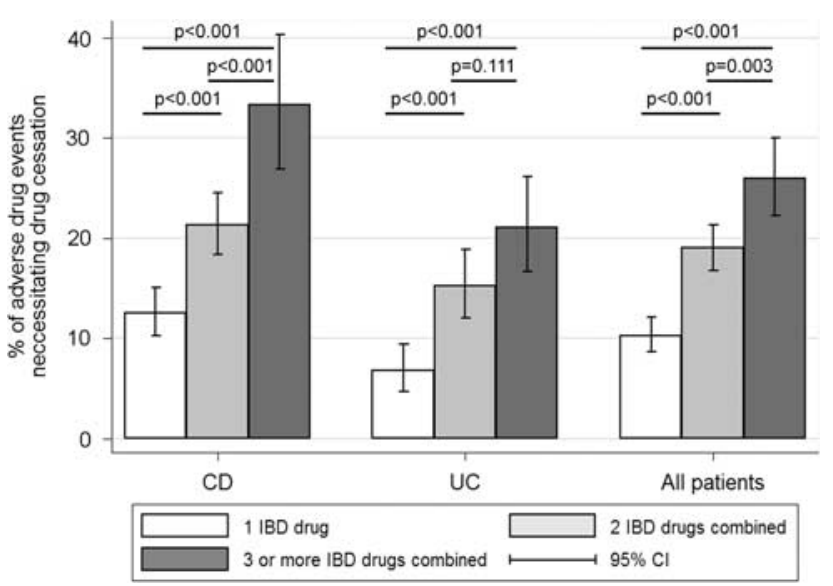

Fig. 2. Frequency of drug adverse events necessitating drug cessation in IBD patients in relation to the number of concomitantly used IBD drugs. CD, Crohn's disease; $\mathrm{Cl}$, confidence interval; IBD, inflammatory bowel disease; UC, ulcerative colitis.

Table 4. Frequency of inflammatory bowel disease drugs-related adverse events in relation to the number of concomitantly used drugs

\begin{tabular}{|c|c|c|c|c|c|c|}
\hline & \multicolumn{2}{|c|}{ CD patients $[n(\%)]$} & \multicolumn{2}{|c|}{ UC patients $[n(\%)]$} & \multicolumn{2}{|c|}{ All patients [n (\%)] } \\
\hline & No side effects & Side effects & No side effects & Side effects & No side effects & Side effects \\
\hline Never treated with combo therapy & $664(87.5)$ & $95(12.5)$ & $441(93.2)$ & $32(6.8)$ & $1105(89.7)$ & $127(10.3)$ \\
\hline Treated with two IBD drugs concomitantly & $561(78.7)$ & $152(21.3)$ & $379(84.8)$ & $68(15.2)$ & $940(81.0)$ & $220(19.0)$ \\
\hline Treated with at least three IBD drugs concomitantly & $134(66.7)$ & 67 (33.3) & $239(78.9)$ & $64(21.1)$ & $373(74.0)$ & $131(26.0)$ \\
\hline
\end{tabular}


Table 5. Logistic regression modeling to identify the factors associated with drug-related adverse events in all inflammatory bowel disease patients during the follow-up period

\begin{tabular}{|c|c|c|c|c|c|c|}
\hline & \multicolumn{3}{|c|}{ Univariate model } & \multicolumn{3}{|c|}{ Multivariate model } \\
\hline & OR & $95 \% \mathrm{Cl}$ & $P$-value & OR & $95 \% \mathrm{Cl}$ & $P$-value \\
\hline \multicolumn{7}{|l|}{ Sex } \\
\hline Male & 1 (ref) & - & - & 1 (ref) & - & - \\
\hline Female & 1.273 & $1.033-1.568$ & 0.024 & 1.172 & $0.941-1.457$ & 0.157 \\
\hline \multicolumn{7}{|l|}{ Age at diagnosis (years) } \\
\hline$<40$ & 1 (ref) & - & - & & & \\
\hline$\geq 40$ & 1.073 & $0.833-1.382$ & 0.586 & & & \\
\hline \multicolumn{7}{|l|}{ Diagnosis } \\
\hline UC & 1 (ref) & - & - & 1 (ref) & - & - \\
\hline$C D$ & 1.541 & $1.239-1.916$ & $<0.001$ & 1.361 & $1.057-1.751$ & 0.017 \\
\hline \multicolumn{7}{|l|}{ Disease duration (years) } \\
\hline$\leq 10$ & 1 (ref) & - & - & 1 (ref) & - & - \\
\hline$>10$ & 1.168 & $0.947-1.442$ & 0.147 & 0.919 & $0.732-1.155$ & 0.470 \\
\hline \multicolumn{7}{|l|}{ IBD family history } \\
\hline No & 1 (ref) & - & - & & & \\
\hline Yes & 0.976 & $0.717-1.329$ & 0.879 & & & \\
\hline \multicolumn{7}{|l|}{ EIM } \\
\hline No & 1 (ref) & - & - & 1 (ref) & - & - \\
\hline Yes & 2.615 & $2.091-3.271$ & $<0.001$ & 2.262 & $1.794-2.852$ & $<0.001$ \\
\hline \multicolumn{7}{|c|}{ Cigarette smoking at diagnosis } \\
\hline Nonsmoker & 1 (ref) & - & - & & & \\
\hline Smoker & 1.074 & $0.867-1.329$ & 0.515 & & & \\
\hline \multicolumn{7}{|l|}{$\mathrm{BMI}$} \\
\hline$<30$ & 1 (ref) & - & - & & & \\
\hline$\geq 30$ & 1.025 & $0.714-1.474$ & 0.892 & & & \\
\hline \multicolumn{7}{|l|}{ IBD-related surgery } \\
\hline No & 1 (ref) & - & - & 1 (ref) & - & - \\
\hline Yes & 1.662 & $1.344-2.054$ & $<0.001$ & 1.419 & $1.107-1.818$ & 0.006 \\
\hline \multicolumn{7}{|c|}{ Ever treated with combo therapy } \\
\hline Never & 1 (ref) & - & - & 1 (ref) & - & - \\
\hline 2-therapy combo & 2.141 & $1.664-2.755$ & $<0.001$ & 2.007 & $1.553-2.595$ & $<0.001$ \\
\hline $3+$-therapy combo & 3.154 & $2.367-4.204$ & $<0.001$ & 3.225 & $2.391-4.349$ & $<0.001$ \\
\hline
\end{tabular}

$\mathrm{CD}$, Crohn's disease; $\mathrm{Cl}$, confidence interval; EIM, extraintestinal manifestation; IBD, inflammatory bowel disease; OR, odds ratio; UC, ulcerative colitis.

Table 3, Supplemental digital content 1, http://links.lww. com/EJGH/A258).

In UC patients, the multivariate model identified the presence of EIM (OR=1.937), IBD-related surgery $(\mathrm{OR}=1.506)$, and the number of concomitantly used IBD drugs $(\mathrm{OR}=2.229$ for two concomitantly used IBD drugs; $\mathrm{OR}=2.991$ for at least three concomitantly used IBD drugs) to be associated significantly with IBD drugrelated side effects requiring drug cessation. Smoking was identified as a protective factor $(\mathrm{OR}=0.525)$ for IBD drug-related side effects.

\section{Discussion}

We present data of a large national cohort study evaluating the frequency and type of IBD drug-related side effects that necessitated treatment discontinuation. Our study yielded several results that are clinically relevant. First, over a median disease duration of 12 years, the majority $(67.8 \%)$ of patients experienced IBD drug-related side effects that required treatment discontinuation. Second, drug-related side effects requiring treatment discontinuation were most frequently observed for thiopurines, followed by methotrexate, TNF-antagonists, cyclosporine, 5-ASA, and steroids. Third, the number of concomitantly used IBD drugs was the strongest predictor for experiencing IBD drug-related side effects necessitating treatment discontinuation.

We first discuss drug-related side effects necessitating treatment cessation according to the observed frequencies of the different drugs. Azathioprine and mercaptopurine are steroid-sparing drugs that have been used to treat CD and UC for over 50 years [14]. We found a frequency of drug-related side effects requiring treatment cessation in $25.1 \%$ of IBD patients treated with azathioprine and in $30.1 \%$ of patients treated with 6 -mercaptopurine (6-MP). Leukopenia, pancreatitis, and gastrointestinal intolerance were the dominant reasons for thiopurine cessation. Our data are in agreement with the study by Chaparro et al. [15], who evaluated the incidence of thiopurine-related adverse events in 3931 patients with a median follow-up of 44 months (range: 0-420 months). They observed a cumulative incidence of adverse events of $26 \%$, with an annual risk of $7 \%$ for patient-year of treatment. The most frequent adverse events were nausea $(8 \%)$, hepatotoxicity $(4 \%)$, myelotoxicity $(4 \%)$, and pancreatitis $(4 \%)$. A total of $17 \%$ of patients had to discontinue thiopurines because of these adverse events [15]. The higher frequency of adverse events leading to thiopurine cessation in the SIBDC can be explained by the longer follow-up in our cohort. The fact that we observed 6-MP-related side effects leading to drug cessation in $30.1 \%$ of treated patients represents a selection bias as 6-MP is mostly used in patients who have already experienced an adverse drug event under azathioprine.

We observed methotrexate-related adverse events leading to drug cessation in $19.8 \%$ of treated patients. Gastrointestinal intolerance (nausea, vomiting, elevated liver enzymes) was the dominant reason $(27 \%)$ to discontinue methotrexate. Our findings are in agreement with the literature reporting that the typical side effects of methotrexate therapy include liver toxicity, dyspnea, 
nausea, vomiting, fatigue, and neutropenia [16]. Goodman et al. [17] found that $30 \%$ of patients treated with methotrexate for at least 5 years discontinued therapy because of adverse effects. Other studies reported a side effect rate as low as $17 \%$, with withdrawal of methotrexate in only $8 \%$ of patients [18]. The rate of discontinuation for methotrexate observed in our cohort is also between these values. It is noteworthy that higher prevalence rates for methotrexaterelated adverse events were observed ( 74 vs. $38 \%$ ) in patients who did not receive folic acid supplementation [18]. The questionnaires of the SIBDC did not systematically assess concomitant supplementation with folic acid.

Monoclonal antibodies directed against TNF- $\alpha$ are used to treat IBD patients with moderate-to-severe clinical activity not responding to conventional medical therapy. Infliximab, adalimumab, and certolizumab pegol are approved for the induction and maintenance of remission in CD [19-21], whereas infliximab, adalimumab, and golimumab are approved for the induction and maintenance of remission in UC [22-24]. Well-known adverse events of anti-TNF therapy are an increased risk of serious and opportunistic infections, infusion reactions (for infliximab), skin reactions (for adalimumab and certolizumab pegol), autoimmunity, heart failure, and risk of melanoma. In our cohort, we observed a discontinuation rate because of side effects of infliximab in $20.6 \%$, certolizumab pegol in $15 \%$, and adalimumab in $14.4 \%$ of patients, respectively. Opportunistic infections were rarely reported in our cohort $(<1 \%$ of treated patients). However, TNF-antagonist therapy is well known to be associated with an increased risk of severe and opportunistic infections in patients with IBD [25]. An analysis from the Crohn's Therapy, Resource, Evaluation, and Assessment Tool (TREAT) registry found that infliximab exposure was associated with severe infections [hazard ratio $(\mathrm{HR})=1.4,95 \% \mathrm{CI}: 1.1-1.8]$ even after adjusting for other factors such as disease activity, steroid use, and narcotic use [26]. In addition to severe infections, IBD patients exposed to TNF-antagonists are also at risk of developing opportunistic infections. A recent meta-analysis of 22 randomized-controlled trials found that opportunistic infections developed in $0.9 \%$ of patients receiving TNF-antagonist therapy versus $0.3 \%$ of patients under placebo (relative risk $=2.1,95 \%$ CI: 1.1-3.9) [27]. Infusion reactions under infliximab leading to drug discontinuation were observed in $2.5 \%$ of treated IBD patients in the SIBDC. These data are in agreement with the literature showing that infusion reactions occur with $3-17 \%$ of infliximab infusions [28]. As shown by Cheifetz et al. [29] in a cohort of 165 patients receiving 479 infusions over a 3-year period, the majority of infusion reactions are mild and rarely lead to infliximab discontinuation. We found injection-site reactions leading to drug discontinuation in $0.2 \%$ of adalimumab-treated patients and in none of the patients treated with certolizumab pegol. Our findings are in agreement with the literature showing that injection-site reactions can occur in up to $5 \%$ of adalimumab-treated patients [27]. In contrast to this finding, patients receiving certolizumab pegol had a lower rate of injection-site reactions than patients receiving placebo (3 vs. 14\%) [28]. Psoriasiform and eczematiform lesions may also develop under TNF-antagonist treatment [30]. We found that $3.5,2.2$, and $4.2 \%$ of IBD patients treated with infliximab, adalimumab, and certolizumab pegol, respectively, discontinued their drug because of skin reactions. These data are again in agreement with studies showing an incidence of eczematiform and psoriatic lesions to be $9-16 \%$ [31]. Of these, up to $34 \%$ of patients ultimately discontinue TNF-antagonist therapy [32].

Cyclosporine and tacrolimus are effective in inducing clinical response and remission in UC patients with severe disease [33]. The main adverse reactions include renal dysfunction, tremor, hirsutism, hypertension, gum hyperplasia, and gastrointestinal intolerance [33]. In our cohort, we found that $13.5 \%$ of patients treated with cyclosporine and/or tacrolimus, respectively, had to discontinue treatment because of adverse events. The most frequently cited reasons for drug discontinuation were hypertension and gastrointestinal intolerance.

Aminosalicylates (5-ASA) are considered to be relatively safe and have similar adverse events compared with placebo. Most frequent adverse events are diarrhea (3\%), headache $(2 \%)$, nausea $(2 \%)$, rash $(1 \%)$, and thrombocytopenia $(<1 \%)$ [6]. In our cohort, a total of $7.9 \%$ of patients discontinued their 5-ASA treatment because of adverse events. The most frequent reasons for 5-ASA discontinuation were nausea/diarrhea $(0.9 \%$ of all 5 -ASAtreated patients), gastrointestinal intolerance $(0.4 \%)$, and nephritis $(0.3 \%)$.

Systemic glucocorticoids are effective in inducing remission in both $\mathrm{CD}$ and $\mathrm{UC}$, whereas they are ineffective in the maintenance of remission in both diseases [34,35]. However, their use is limited by their frequent side effects [36]. The most frequent side effects occur in the skin, such as thinning of the skin or purpura. Steroids can induce both osteoporosis and osteonecrosis. Furthermore, they increase the susceptibility to various fungal, viral, and bacterial infections. Steroids can cause various psychologic complications such as depression, insomnia, or euphoria. Other potential side effects include myopathy, cushingoid features, redistribution of body fat, hyperlipidemia, hyperglycemia or overt diabetes, and ophthalmologic complications such as cataract or glaucoma. Despite the high prevalence of steroid-related side effects described in the literature, only 5.3 and $4.7 \%$ of patients treated with topical and systemic steroids discontinued these drugs because of side effects in our cohort. The most frequent reasons for glucocorticosteroid discontinuation were cushingoid features $(0.6 \%$ of all steroid-treated IBD patients), gastrointestinal intolerance $(0.4 \%$ of all steroidtreated IBD patients), osteoporosis/osteopenia (0.2\%), psychosis $(0.2 \%)$, edema $(0.2 \%)$, and diabetes $(0.1 \%$ of all steroid-treated IBD patients). We were intrigued that, despite the large variety of possible side effects, the discontinuation rate for steroids in our cohort was even lower than the one for 5-ASA. This finding might be explained by the fact that steroids are typically used for induction of response and remission and not for maintenance treatments, which is in contrast to the use of the other drugs described above.

We identified UC diagnosis $(\mathrm{OR}=0.735)$, presence of EIM $(O R=2.262)$, IBD-related surgery $(O R=1.419)$, and the increasing number of concomitantly used IBD drugs $(\mathrm{OR}=2.007$ for two concomitantly used IBD drugs; $\mathrm{OR}=3.225$ for at least three concomitantly used IBD drugs) to be associated significantly with the occurrence of 
IBD drug-related adverse events that necessitated drug cessation. It is noteworthy that the use of at least three concomitantly used IBD drugs showed the strongest association with IBD drug-related adverse events necessitating treatment discontinuation. The SONIC trial showed that a greater proportion of immunomodulator and biologic-naive patients with moderate-to-severe $\mathrm{CD}$ who were treated with a combination of azathioprine and infliximab achieved steroid-free remission at 6 months compared with patients treated with infliximab or azathioprine alone ( 75 vs. 44 vs. $30 \%$ ) [9]. In this trial, the rates of serious infections were similar between azathioprine alone, infliximab alone, and the combination therapy $(4.6,4.9$, and $3.9 \%$ ) [9]. However, an analysis of CD patients who were treated with steroids, immunomodulators, and/or anti-TNF- $\alpha$ agents found that CD patients receiving at least two of these drugs had higher rates of infections including tuberculosis $(\mathrm{HR}=7.4 ; 95 \%$ CI: 2.1-26), candidiasis ( $\mathrm{HR}=3.8 ; 95 \%$ CI: $2.0-7.6)$, and herpes zoster ( $\mathrm{HR}=3.7 ; 95 \% \mathrm{CI}: 1.8-7.5)$ compared with control patients and patients receiving only one of these drugs [26].

Our study does have strengths and some limitations as well. We present data from a large national cohort with a median disease duration of 12 years. We report on the frequency and type of drug-related side effects necessitating treatment discontinuation, which represents a strong outcome. To the best of our knowledge, this is the first large cohort study that convincingly shows the increased risk developing adverse drug events requiring treatment discontinuation when combining different IBD drugs. As a first limitation, the SIBDCS is not population based as $80 \%$ of patients are recruited in a hospital setting and only $20 \%$ of patients are recruited by gastroenterologists in private practice. Therefore, data cannot be generalized to the entire IBD population. Second, the follow-up questionnaires of the SIBDCS do not capture detailed information on the duration of the different treatments, nor do they assess, for example, blood levels of metabolites of azathioprines and neither drug levels of TNF-antagonists. Third, data capture once a year may also predispose to under-reporting of events.

\section{Conclusion}

Over a median disease duration of 12 years, two-thirds of patients experienced IBD drug-related side effects that required treatment discontinuation. Drug-related side effects necessitating treatment discontinuation were most frequently observed for thiopurines, followed by methotrexate, TNFantagonists, cyclosporine, 5-ASA, and steroids. The number of concomitantly used IBD drugs was the strongest predictor for experiencing IBD drug-related side effects necessitating treatment discontinuation. Physicians involved in the care of patients with IBD should maintain a high level of awareness of the potential occurrence of drug-related side effects in the follow-up of their patients, particularly when combining different IBD drugs.

\section{Acknowledgements}

The authors thank all members of the SIBDCS who were involved in the acquisition of data: Claudia Anderegg; Peter Bauerfeind; Christoph Beglinger; Stefan Begré;
Dominique Belli; José Bengoa; Luc Biedermann; Janek Binek; Mirjam Blattmann; Nadia Blickenstorfer; Stephan Boehm; Jan Borovicka; Christian Braegger; Patrick Bühr; Bernard Burnand; Emmanuel Burri; Sophie Buyse; Matthias Cremer; Dominique Criblez; Philippe de Saussure; Lukas Degen; Joakim Delarive; Christopher Dörig; Barbara Dora; Tobias Ehmann; Ali El Wafa; Mara Egger; Matthias Engelmann; Christian Felley; Markus Fliegner; Nicolas Fournier; Montserrat Fraga; Alain Frei; Pascal Frei; Remus Frei; Michael Fried; Florian Froehlich; Raoul Furlano; Suzanne Gallot-Lavallée; Martin Geyer; Marc Girardin; Delphine Golay; Tanja Grandinetti; Beat Gysi; Horst Haack; Johannes Haarer; Beat Helbling; Peter Hengstler; Denise Herzog; Cyrill Hess; Klaas Heyland; Thomas Hinterleitner; Philippe Hiroz; Claudia Hirschi; Petr Hruz; Pascal Juillerat; Rosmarie Junker; Christina Knellwolf; Christoph Knoblauch; Henrik Köhler; Rebekka Koller; Claudia Krieger; Gerd A. Kullak-Ublick; Markus Landolt; Frank Lehmann; Valérie McLin; Philippe Maerten; Michel Maillard; Christine Manser; Urs Marbet; Michael Manz; George Marx; Rémy Meier; Christa Meyenberger; Jonathan Meyer; Pierre Michetti; Benjamin Misselwitz; Darius Moradpour; Patrick Mosler; Christian Mottet; Christoph Müller; Pascal Müller; Beat Müllhaupt; Claudia Münger; Leilla Musso; Andreas Nagy; Cristina Nichita; Natacha Noël; Andreas Nydegger; Maliza Nzabonimpa; Nicole Obialo; Carl Oneta; Cassandra Oropesa; Laetitia-Marie Petit; Franziska Piccoli; Julia Pilz; Gaëlle Pittet; Valérie Pittet; Bruno Raffa; Ronald Rentsch; Sophie Restellini, Jean-Pierre Richterich; Silvia Rihs; Jocelyn Roduit; Daniela Rogler; Gerhard Rogler; JeanBenoît Rossel; Markus Sagmeister; Gaby Saner; Bernhard Sauter; Mikael Sawatzki; Michael Scharl; Sylvie Scharl; Nora Schaub; Martin Schelling; Susanne Schibli; Hugo Schlauri; Daniela Schmid; Sybille Schmid; Jean-François Schnegg; Alain Schoepfer; Christiane Sokollik; Frank Seibold; Gian-Marco Semadeni; Mariam Seirafi; David Semela; Arne Senning; Marc Sidler; Johannes Spalinger; Holger Spangenberger; Philippe Stadler; Volker Stenz; Michael Steuerwald; Alex Straumann; Michael Sulz; Alexandra Suter; Michela Tempia-Caliera; Joël Thorens; Sarah Tiedemann; Stephan Vavricka; Francesco Viani; Roland Von Känel; Alain Vonlaufen; Dominique Vouillamoz; Rachel Vulliamy; Helene Werner; Paul Wiesel; Reiner Wiest; Tina Wylie; Jonas Zeitz; Dorothee Zimmermann.

All authors contributed to study concept, design, analysis and interpretation of data, and critical revision of the manuscript for important intellectual content. Sébastien Godat, Nicolas Fournier, Pascal Juillerat, Andreas Nydegger, Alex Straumann, Stephan Vavricka, Luc Biedermann, Thomas Greuter, Montserrat Fraga, Karim Abdelrahman, Dieter Hahnloser, Bernhard Sauter, Gerhard Rogler, Pierre Michetti, and Alain M. Schoepfer contributed to acquisition of data; Sébastien Godat, Nicolas Fournier, Ekaterina Safroneeva, and Alain M. Schoepfer drafted the manuscript; Sébastien Godat, Nicolas Fournier, Ekaterina Safroneeva, Pierre Michetti, and Alain M. Schoepfer carried out the statistical analysis; Alain M. Schoepfer conducted the technical, or material support; Sébastien Godat and Alain M. Schoepfer supervised the study.

This work was supported by grants from the Swiss National Science Foundation (33CS30_148422 to Swiss 
IBD Cohort Study group, 32003B_160115/1 to A.M.S.) and unrestricted research grants from Otsuka Switzerland, Takeda Switzerland, and Tillotts Switzerland.

\section{Conflicts of interest}

There are no conflicts of interest.

\section{References}

1 Dignass A, van Assche G, Lindsay JO, Lémann M, Söderholm J, Colombel JF, et al. European Crohn's and Colitis Organisation (ECCO). The second European evidence-based Consensus on the diagnosis and management of Crohn's disease: current management. J Crohns Colitis 2010; 4:28-62.

2 Dignass A, Lindsay JO, Sturm A, Windsor A, Colombel JF, Allez M, et al Second European evidence-based consensus on the diagnosis and management of ulcerative colitis part 2: current management. J Crohns Colitis 2012; 6:991-1030.

3 Domenèch $\mathrm{E}$, Manosa $\mathrm{M}$, Cabré $\mathrm{E}$. An overview of the natural history of inflammatory bowel diseases. Dig Dis 2014; 32:320-327.

4 Ferrante M, Karmiris K, Newnham E, Siffledeen J, Zelinkova Z, van Assche G, et al. Physician perspectives on unresolved issues in the use of conventional therapy in Crohn's disease: results from an international survey and discussion programme. J Crohns Colitis 2012; 6:116-131.

5 Bossuyt $\mathrm{P}$, Vermeire $\mathrm{S}$. Treat to target in inflammatory bowel disease. Curr Treat Options Gastroenterol 2016; 14:61-72.

6 Rogler G. Gastrointestinal and liver adverse effects of drugs used for treating IBD. Best Pract Res Clin Gastroenterol 2010; 24:157-165.

7 Moran GW, Lim AW, Bailey JL, Dubeau MF, Leung Y, Devlin SM, et al. Review article: dermatological complications of immunosuppressive and anti-TNF therapy in inflammatory bowel disease. Aliment Pharmacol Ther 2013; 38:1002-1024.

8 Hindorf $\mathrm{U}$, Lindqvist $\mathrm{M}$, Hildebrand $\mathrm{H}$, Fagerberg $\mathrm{U}$, Almer $\mathrm{S}$. Adverse events leading to modification of therapy in a large cohort of patients with inflammatory bowel disease. Aliment Pharmacol Ther 2006; 24:331-342.

9 Colombel JF, Sandborn WJ, Reinisch W, Mantzaris GJ, Kornbluth A, Rachmilewitz D, et al. Infliximab, azathioprine, or combination therapy for Crohn's disease. N Engl J Med 2010; 362:1383-1395.

10 Bar-Yoseph H, Waterman M, Almog R, Billiet T, Vermeire S, Ungar B, et al. Prevention of anti-drug antibody formation to infliximab in Crohn's disease patients with prior failure to thiopurines. Clin Gastroenterol Hepatol 2017; 15:69-75.

11 Osterman MT, Sandborn WJ, Colombel JF. Increased risk of malignancy with adalimumab combination therapy, compared with monotherapy, for Crohn's disease. Gastroenterology 2014; 146:941-949.

12 Pittet V, Juillerat $\mathrm{P}$, Mottet $\mathrm{C}$, Felley $\mathrm{C}$, Ballabeni $\mathrm{P}$, Burnand B, et al. Cohort profile: the Swiss Inflammatory Bowel Disease Cohort Study (SIBDCS). Int J Epidemiol 2009; 38:922-931.

13 Silverberg MS, Satsangi J, Ahmad T, Arnott ID, Bernstein CN, Brant SR, et al. Toward an integrated clinical, molecular and serological classification of inflammatory bowel disease: Report of a Working Party of the 2005 Montreal World Congress of Gastroenterology. Can J Gastroenterol 2005; 19 (Suppl A):5A-36A.

14 Kennedy NA, Rhatigan E, Arnott ID, Noble CL, Shand AG, Satsangi J, et al. A trial of mercaptopurine is a safe strategy in patients with inflammatory bowel disease intolerant to azathioprine: an observational study, systematic review, and meta-analysis. Aliment Pharmacol Ther 2013; 38:1255-1266.

15 Chaparro M, Ordás I, Cabré E, Garcia-Sanchez V, Bastida G, Peñalva $\mathrm{M}$, et al. Safety of thiopurine therapy in inflammatory bowel disease: long-term follow-up study of 3931 patients. Inflamm Bowel Dis 2013; 19:1404-1410.

16 Wahed M, Louis-Auguste JR, Baxter LM, Limdi JK, McCartney SA, Lindsay JO, et al. Efficacy of methotrexate in Crohn's disease and ulcerative colitis patients unresponsive or intolerant to azathioprine/ mercaptopurine. Alim Pharmacol Ther 2009; 30:614-620.

17 Goodman TA, Polisson RP. Methotrexate: adverse reactions and major toxicities. Rheum Dis Clin North Am 1994; 20:513-528.

18 Saibeni S, Bollani S, Losco A, Michielan A, Sostegni R, Devani M, et al. The use of methotrexate for treatment of inflammatory bowel diseases in clinical practice. Dig Liver Dis 2012; 44:123-127.

19 Hanauer SB, Feagan BG, Lichtenstein GR, Mayer LF, Schreiber S, Colombel JF, et al. Maintenance infliximab for Crohn's disease: the ACCENT I randomized trial. Lancet 2002; 359:1541-1549.

20 Colombel JF, Sandborn WJ, Rutgeerts P, Enns R, Hanauer SB, Panaccione R, et al. Adalimumab for maintenance of clinical response and remission in patients with Crohn's disease: the CHARM trial. Gastroenterology 2007; 132:52-65.

21 Sandborn WJ, Feagan BG, Stoinov S, Honiball PJ, Rutgeerts P, Mason D, et al. Certolizumab pegol for the treatment of Crohn's disease. N Engl J Med 2007; 357:228-238.

22 Rutgeerts P, Sandborn WJ, Feagan BG, Reinisch W, Olson A, Johanns $\mathrm{J}$, et al. Infliximab for induction and maintenance therapy for ulcerative colitis. N Engl J Med 2005; 353:2462-2476.

23 Sandborn WJ, van Assche G, Reinisch W, Colombel JF, D'Haens G, Wolf DC, et al. Adalimumab induces and maintains clinical remission in patients with moderate-to-severe ulcerative colitis. Gastroenterology 2012; 142:257-265.

24 Sandborn WJ, Feagan BG, Marano C, Zhang H, Strauss R, Johanns J, et al. Subcutaneous golimumab induces clinical response and remission in patients with moderate-to-severe ulcerative colitis. Gastroenterology 2014; 146:85-95

25 Marehbian J, Arrighi HM, Hass S, Tian H, Sandborn WJ. Adverse events associated with common therapy regimens for moderate-to-severe Crohn's disease. Am J Gastroenterol 2009; 104:2524-2533.

26 Lichtenstein GR, Feagan BG, Cohen RD, Salzberg BA, Diamond RH, Price $\mathrm{S}$, et al. Serious infections and mortality in patients with Crohn's disease: more than 5 years of follow-up in the TREAT ${ }^{\mathrm{TM}}$ registry. Am J Gastroenterol 2012; 107:1409-1422.

27 Ford AC, Peyrin-Biroulet L. Opportunistic infections with anti-tumor necrosis factor-alpha therapy in inflammatory bowel disease: metaanalysis of randomized controlled trials. Am J Gastroenterol 2013; 108:1268-1276.

28 Colombel JF, Loftus EV Jr, Tremaine WJ, Egan LJ, Harmsen WS, Schleck CD, et al. The safety profile of infliximab in patients with Crohn's disease: the Mayo Clinic experience in 500 patients. Gastroenterology 2004; 126:19-31.

29 Cheifetz A, Smedley M, Martin S, Reiter M, Leone G, Mayer L, et al. The incidence and management of infusion reactions to infliximab: a large center experience. Am J Gastroenterol 2003; 98:1315-1324.

30 Protic M, Schoepfer A, Yawalkar N, Vavricka S, Seibold F. Development of psoriasis in IBD patients under TNF-antagonist therapy is associated neither with anti-TNF-antagonist antibodies nor trough levels. Scand J Gastroenterol 2016; 51:1482-1488.

31 Fidder H, Schnitzler F, Ferrante M, Noman M, Katsanos K, Segaert S, et al. Long-term safety of infliximab for the treatment of inflammatory bowel disease: a single-center cohort study. Gut 2009; 58:501-508.

32 Rahier JF, Buche S, Peyrin-Biroulet L, Bouhnik Y, Duclos B, Louis E, et al. Severe skin lesions cause patients with inflammatory bowel disease to discontinue anti-tumor necrosis factor therapy. Clin Gastroenterol Hepatol 2010; 8:1048-1055.

33 Garcia-Lopez S, Gomollon-Garcia F, Perez-Gisbert J. Cyclosporine in the treatment of severe attack of ulcerative colitis : a systematic review. Gastroenterol Hepatol 2005; 28:607-614.

34 Scribano M, Prantera C. Review article: medical treatment of moderate to severe Crohn's disease. Aliment Pharmacol Ther 2003; 17 (Suppl 2): 23-30.

35 Jewell DP. Corticosteroids for the management of ulcerative colitis and Crohn's disease. Gastroenterol Clin North Am 1989; 18:21-34.

36 Curkovic I, Egbring M, Kullak-Ublick GA. Risks of inflammatory bowel disease treatment with glucocorticosteroids and aminosalicylates. Dig Dis 2013; 31:368-373. 